\title{
Bulk-heterojunction organic photovoltaic cells fabricated using a high-viscosity solution of poly(3-hexylthiophene) with extremely high molecular weight
}

Polymer Journal (2013) 45, 129-132; doi:10.1038/pj.2012.182; published online 21 November 2012

\section{INTRODUCTION}

Organic photovoltaic cells (OPVs) offer to be a promising source of electrical energy owing to their low fabrication cost and ease of processing on flexible substrates. ${ }^{1-8}$ The most promising OPV is that based on regioregular poly(3-hexylthiophene) (P3HT) as a donor material blended with the soluble fullerene, (6,6)-phenyl C61 butyric acid methyl ester $\left(\mathrm{PC}_{60} \mathrm{BM}\right)$, as an acceptor material to form a bulk-heterojunction (BHJ) layer. ${ }^{9,10}$ Many researchers have investigated the influence of weight average molecular weight $\left(M_{\mathrm{w}}\right)$ on the performance of P3HT:PC ${ }_{60} \mathrm{BM}$-based $\mathrm{BHJ}$ OPVs to obtain high performance. ${ }^{1-13}$ For example, Schilinsky et al. ${ }^{14}$ characterized BHJ OPVs using P3HTs with a $M_{\mathrm{w}}$ ranging from 3100 to 25700 . They found that high powerconversion efficiencies (PCEs) of $>2.5 \%$ were obtained for P3HTs with an $M_{\mathrm{w}}$ of $>20400$. Hiorns et al. ${ }^{15}$ characterized BHJ OPVs using P3HTs with an $M_{\mathrm{w}}$ ranging from 5400 to 308000 and found that an optimized annealing temperature was required for increased performance due to the high $M_{\mathrm{w}}$. Overall, these previous works have demonstrated a strong correlation between photovoltaic performance, the $M_{\mathrm{w}}$ of a $\pi$-conjugated polymer and the aggregation state of the polymer in $\mathrm{PC}_{60} \mathrm{BM}$-blended films.

In the present work, we focused on P3HT with a high $M_{\mathrm{w}}$, which has a high viscosity in solution. We demonstrated that the amount of both donor and acceptor materials in the fabrication of BHJ OPVs could be strongly reduced using a high-viscosity $\mathrm{P} 3 \mathrm{HT}$ solution with an $M_{\mathrm{w}}$ of 680900 . In addition, only slight fluctuations were observed in PCEs of around 3.8\% for all OPVs based on P3HT for $M_{\mathrm{w}}$ ranging from 46600 to 680900 . In this way, we found that a higher $M_{\mathrm{w}}$ possessed advantages over low $M_{\mathrm{w}}$ P3HT compounds in the OPV fabrication process.

\section{EXPERIMENTAL PROCEDURE}

P3HT batches with different $M_{\mathrm{w}}$ were supplied by Soken Chemical \& Engineering Co., Ltd (Sayama, Japan). Synthesis of these P3HTs will be reported in due course. P3HT batches in this study had the following properties, where $M_{\mathrm{n}}$ corresponds to number average molecular weight determined by gel permeation chromatography (GPC) using polystyrene standards (HLC-8320GPC EcoSEC, Tosoh Co., Tokyo, Japan), PD is polydispersity and RR is regioregularity: $M_{\mathrm{w}} / M_{\mathrm{n}}=46600 / 23000$ with $\mathrm{PD}=2.03$ and $\mathrm{RR}=98 \%, \quad M_{\mathrm{w}} / M_{\mathrm{n}}=341400 /$ 140400 with $\mathrm{PD}=2.43$ and $\mathrm{RR}=99 \%$, and $M_{\mathrm{w}} /$ $M_{\mathrm{n}}=680900 / 208600$ with $\mathrm{PD}=3.26$ and $\mathrm{RR}=99 \%$, labeled low $\left(\mathrm{L}-M_{\mathrm{w}}\right)$, middle $\left(\mathrm{M}-M_{\mathrm{w}}\right)$, and high $\left(\mathrm{H}-\mathrm{M}_{\mathrm{w}}\right)$ molecular weight samples, respectively. As a reference material, commercially available P3HT (synthesized by Rieke method) ${ }^{16}$ with $M_{\mathrm{w}} / M_{\mathrm{n}}=48100 / 24400, \quad \mathrm{PD}=2.00$ and $\mathrm{RR}=95 \%$, labeled $\mathrm{R}-M_{\mathrm{w}}$, was purchased from Rieke Metals Inc., Lincoln, NE, USA. These P3HT parameters are summarized in Table 1. Poly(3,4-ethylenedioxythiophene)-poly(styrenesulfonate) (PEDOT:PSS, CLEVIOS P VP AI 4083) was purchased from Heraeus (Leverkusen, Germany). $\mathrm{PC}_{60} \mathrm{BM}$ (purity 99\%) was purchased from Solenne (Groningen, Netherlands).

BHJ OPVs were fabricated in the following configuration, where ITO corresponds to indium tin oxide: ITO/PEDOT:PSS/BHJ layer/LiF/Al. The patterned ITO ( $10 \Omega$ /square conductivity) glass was pre-cleaned in an ultrasonic bath of acetone and ethanol and then treated in an ultraviolet/ozone chamber. A thin layer $(40 \mathrm{~nm})$ of PEDOT:PSS was spin coated at 3000 r.p.m. and subsequently dried at $110^{\circ} \mathrm{C}$ for $10 \mathrm{~min}$ on a hot plate in air. Substrates were transferred to an $\mathrm{N}_{2}$ glove box and then dried again at $110^{\circ} \mathrm{C}$ for $10 \mathrm{~min}$ on a hot plate. An o-dichlorobenzene (o-DCB) and P3HT:PCBM blend (1:1 ratio by weight) was subsequently spin coated onto the PEDOT:PSS surface, forming a BHJ layer. The solution concentration was changed to maintain the same thickness for all BHJ layers under constant spin coating conditions (600 r.p.m. for 60 s). The substrates with the $\mathrm{BHJ}$ layers were dried for $10 \mathrm{~min}$ at $110^{\circ} \mathrm{C}$ for the film spin coated from $o$-DCB in the $\mathrm{N}_{2}$ glove box. Finally, $\mathrm{LiF}(1 \mathrm{~nm})$ and $\mathrm{Al}(80 \mathrm{~nm})$ were deposited onto the BHJ layer using a conventional thermal evaporation at a chamber pressure lower than $5 \times 10^{-4} \mathrm{~Pa}$. In this way, devices with an active area of $2 \times 2 \mathrm{~mm}^{2}$ were obtained.

Current density-voltage $(J-V)$ curves were measured using an ADCMT 6244 DC Voltage Current Source/Monitor under simulated AM 1.5 solar light irradiation at $100 \mathrm{~mW} \mathrm{~cm}^{-2}$ (OTENTOSUN III, Bunkoh-Keiki Co., Ltd., Tokyo, Japan). Viscosity measurements for each P3HT solution were carried out using a sine-wave vibro viscometer (A\&D Company, Tokyo, Japan). For all measurements, a 5 - $\mathrm{mg} \mathrm{ml}^{-1} o$-DCB solution was prepared and measured at $24.5^{\circ} \mathrm{C}$ under a constant frequency of $30 \mathrm{~Hz}$. Film thickness was measured using an automatic microfigure-measuring instrument (Surfcorder ET200, Kosaka Laboratory Ltd., Tokyo, Japan). Surface morphology was studied using an atomic force microscope (Nanocute, SII NanoTechnology Inc., Chiba, Japan). UV-vis absorption spectra were recorded on a U-3010 spectrometer (Hitachi High-Technologies Co., Tokyo, Japan).

\section{RESULTS AND DISSCUSSION}

As listed in Table 1, the viscosity of the P3HT solution changed from 2.12 to $6.34 \mathrm{mPas}$ with increasing $M_{\mathrm{w}}$. In general, inks are required to possess low viscosity for inkjet printing, whereas the coating solution for screen printing is required to have a relatively 
high viscosity. ${ }^{17}$ Thus, the $\mathrm{P} 3 \mathrm{HT}$ solutions in this study were found to be useful in the many fabrication routes for solutionprocessable OPVs, as they could be prepared with various viscosities. For spin coating, the film thickness $(t)$ is known to depend mainly on rotational speed and viscosity, which is related to $M_{\mathrm{w}}$ and solute concentration as expressed by the empirical relationship:

$$
t=k \omega^{\alpha},
$$

where $\omega$ is the angular velocity, and $k$ and $\alpha$ are empirical constants. Typically, $\alpha$ has a value of around -0.5 and the constant $k$, which contains many parameters such as the initial viscosity of the solution, increases for higher viscosity solutions. ${ }^{17}$ Thus, to achieve a consistent thickness by spin coating at the same rotational speed, the solution concentration was changed with the $\mathrm{P} 3 \mathrm{HT}$ solution viscosity over a range of $M_{\mathrm{w}}$

For example, as listed in Table 2, to obtain a 250-nm-thick BHJ layer, the P3HT: $\mathrm{PC}_{60} \mathrm{BM}$ ratio was $20 \mathrm{mg}: 20 \mathrm{mg} \mathrm{ml}^{-1}$ for $\mathrm{L}-M_{\mathrm{W}}$ and $\mathrm{R}-M_{\mathrm{w}}$ P3HT, $12 \mathrm{mg}: 12 \mathrm{mg} \mathrm{ml}^{-1}$ for $\mathrm{M}-M_{\mathrm{w}}$ P3HT and $9 \mathrm{mg}: 9 \mathrm{mg} \mathrm{ml}^{-1}$ for $\mathrm{H}-M_{\mathrm{w}}$ P3HT. In this way, we demonstrated that amounts of both donor and acceptor materials in the fabrication of BHJ OPVs can be reduced using a high-viscosity P3HT solution. This observation could lead to further reductions in the cost of OPV fabrication. Moreover, the ability to reduce the amount of acceptor material has the advantage that an acceptor material with low solubility in common organic solvents can be used for fabricating BHJ OPVs.

Film properties and device performance of BHJ OPVs based on H- $M_{\mathrm{w}}$ P3HT $\left(M_{\mathrm{w}} /\right.$ $\left.M_{\mathrm{n}}=680900 / 208600\right)$ is another major concern, as the PCE of a BHJ OPV based on P3HT with $M_{\mathrm{w}} / M_{\mathrm{n}}=308000 / 280000$ was reported to be lower than that with $M_{\mathrm{w}} / M_{\mathrm{n}}=31100 / 14800 .{ }^{15}$ The normalized optical absorption spectra of P3HT:PC ${ }_{60} \mathrm{BM}$ (1:1) for four films are shown in Figure 1. The absorbance spectra of the L- $M_{\mathrm{w}}$ P3HT displayed red-shifted absorption peaks with vibrational fine structures, such as shoulder peaks on each side of the maximum absorbance peak. These features are known to be enhanced by the coplanarization of polymer chains due to the ease of crystallization in P3HT with a low $M_{\mathrm{w}}$ and the corresponding $\pi$-electron delocalization. A comparison of the spectra of the P3HT films with L- $M_{\mathrm{w}}$ and $\mathrm{R}-M_{\mathrm{w}}$ reveals that the former has pronounced vibronic peaks, indicating strong interchain interactions among $\mathrm{P} 3 \mathrm{HT}$ chains due to the higher regioregularity in L- $M_{\mathrm{W}}$ P3HT. $^{18}$ The lack of red shifts and fine vibronic peaks in the absorption maxima of $\mathrm{M}-M_{\mathrm{w}}$ and $\mathrm{H}-M_{\mathrm{w}}$ P3HT films is due to an entanglement effect observed in $\mathrm{H}-M_{\mathrm{w}}$ polymers, in sharp contrast to L- $M_{\mathrm{W}} \mathrm{P} \mathrm{HTT}^{15}$

Atomic force microscopy images for the $\mathrm{BHJ}$ layers of $\mathrm{R}-M_{\mathrm{w}}$ and $\mathrm{L}-M_{\mathrm{w}}$ P3HT:PC ${ }_{60} \mathrm{BM}$ in Figure $2 \mathrm{a}$ and $\mathrm{b}$ show a significant roughness, indicating the presence of $\mathrm{P} 3 \mathrm{HT}$ and $\mathrm{PC}_{60} \mathrm{BM}$ aggregates from the ease of crystallization in P3HT with a low $M_{\mathrm{w}}$. In contrast, homogeneous surfaces were

observed for the BHJ layers with $\mathrm{M}-M_{\mathrm{w}}$ and $\mathrm{H}-M_{\mathrm{w}}$ P3HT:PC ${ }_{60} \mathrm{BM}$ as shown in Figure $2 \mathrm{c}$ and $\mathrm{d}$. The lack of absorption shifts and the homogeneous surfaces observed for the films based on $\mathrm{M}-M_{\mathrm{w}}$ and $\mathrm{H}-M_{\mathrm{w}} \mathrm{P} 3 \mathrm{HT}$ indicate that the $\mathrm{P} 3 \mathrm{HT}$ and $\mathrm{PC}_{60} \mathrm{BM}$ are homogenously intermixed and the polymer exhibits a low electronic coupling between neighboring polymer chains.

Figure 3 shows the $J-V$ curves of OPVs based on P3HT:PC ${ }_{60} \mathrm{BM}$ blends with various

Table 1 Characteristics of the four P3HT samples used in this study

\begin{tabular}{lccccc}
\hline Materials & $\mathrm{M}_{w}\left(\mathrm{gmol}^{-1}\right) \mathrm{GPC}(\mathrm{LS})^{\mathrm{a}}$ & $\mathrm{M}_{n}\left(\mathrm{gmol}^{-1}\right) \mathrm{GPC}$ & $P D\left(\mathrm{M}_{w} \mathrm{M}_{n}\right) \mathrm{GPC}$ & $R R(\%)$ & ${\text { Viscosity }(m P a s)^{\mathrm{b}}}^{\mathrm{R}}$ \\
\hline $\mathrm{R}-M_{\mathrm{w}}$ & 48100 & 24400 & 2.00 & 95 & - \\
$\mathrm{L}-M_{\mathrm{w}}$ & $46600(24440)$ & 23000 & 2.03 & 98 & 2.12 \\
$\mathrm{M}-M_{\mathrm{w}}$ & $341400(224600)$ & 140400 & 2.43 & 99 & 4.84 \\
$\mathrm{H}-M_{\mathrm{w}}$ & $680900(425900)$ & 208600 & 3.26 & 99 & 6.34
\end{tabular}

Abbreviations: GPC, gel permeation chromatography; H- $M_{\mathrm{w}}$, high molecular weight; L- $M_{\mathrm{w}}$, low molecular weight; LS, light scattering; $\mathrm{M}-M_{\mathrm{w}}$, middle molecular weight; $\mathrm{PD}$, polydispersity; R- $M_{\mathrm{w}}$, reference molecular weight; RR, regioregularity. a Absolute $M_{\mathrm{w}}$ determined by laser light scattering instruments (DAWN-HELEOS, Wyatt Technology Co., Santa Barbara, CA, USA). b $5 \mathrm{mg} \mathrm{ml}^{-1}$ o-DCB solution at $24.5^{\circ} \mathrm{C}$

Table 2 Thickness, surface roughness (RMS) of BHJ layers based on P3HT:PC 60 BM (1:1) and performance of BHJ OPVs

\begin{tabular}{|c|c|c|c|c|c|c|c|}
\hline BHJ layer & $\begin{array}{c}\text { Concentration } \\
\text { of } \\
\text { solution } \\
\left(m g \mathrm{ml}^{-1}\right)\end{array}$ & $\begin{array}{c}\text { Thickness } \\
(n m)^{a}\end{array}$ & $R M S(n m)$ & $\begin{array}{c}\mathrm{J}_{s c} \\
\left(m A c m^{-2}\right)\end{array}$ & $\mathrm{V}_{o c}(V)$ & $F F$ & PCE (\%) \\
\hline $\mathrm{R}-M_{\mathrm{w}} \mathrm{P} 3 \mathrm{HT}: \mathrm{PC}_{60} \mathrm{BM}$ & $20: 20$ & 242 & 9.03 & 10.27 & 0.59 & 0.60 & 3.64 \\
\hline L-M $M_{\mathrm{w}}$ P3HT:PC $60 \mathrm{BM}$ & $20: 20$ & 228 & 16.52 & 11.12 & 0.54 & 0.64 & 3.83 \\
\hline $\mathrm{M}-M_{\mathrm{w}} \mathrm{P} 3 \mathrm{HT}: \mathrm{PC}_{60} \mathrm{BM}$ & $12: 12$ & 264 & 5.96 & 11.32 & 0.55 & 0.61 & 3.84 \\
\hline $\mathrm{H}-M_{\mathrm{w}}$ P3HT:PC $60 \mathrm{BM}$ & $9: 9$ & 243 & 4.47 & 11.35 & 0.55 & 0.61 & 3.85 \\
\hline
\end{tabular}

Abbreviations: $\mathrm{BHJ}$, bulk-heterojunction; $\mathrm{H}-M_{\mathrm{w}}$, high molecular weight; $\mathrm{L}-M_{\mathrm{w}}$, low molecular weight; $\mathrm{M}-M_{\mathrm{w}}$, middle molecular weight; OPV, organic photovoltaic cells; $\mathrm{PC}_{60} \mathrm{BM},(6,6)$-phenyl $\mathrm{C} 61$ butyric acid methyl ester; PCE, power-conversion efficiency; $\mathrm{P} 3 \mathrm{HT}$, poly(3-hexylthiophene); RMS, root mean square; R- $M_{\mathrm{w}}$, reference molecular weight.

aThe thickness was obtained by spin coating from the solution at 600 r.p.m. for 60 s.

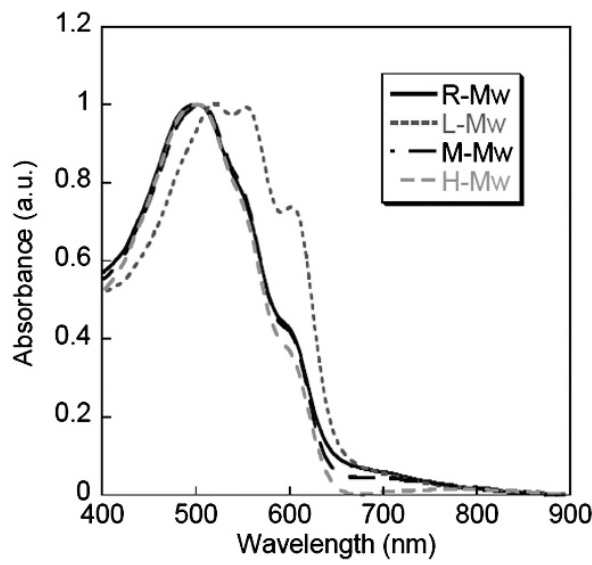

Figure 1 Normalized optical absorption spectra of $\mathrm{P} 3 \mathrm{HT}: \mathrm{PC}_{60} \mathrm{BM}$ (1:1) films fabricated by spin coating from o-DCB solutions at 600 r.p.m. for $60 \mathrm{~s}$ and then annealed at $110{ }^{\circ} \mathrm{C}$ for $10 \mathrm{~min}$. A full color version of this figure is available at Polymer Journal online. 

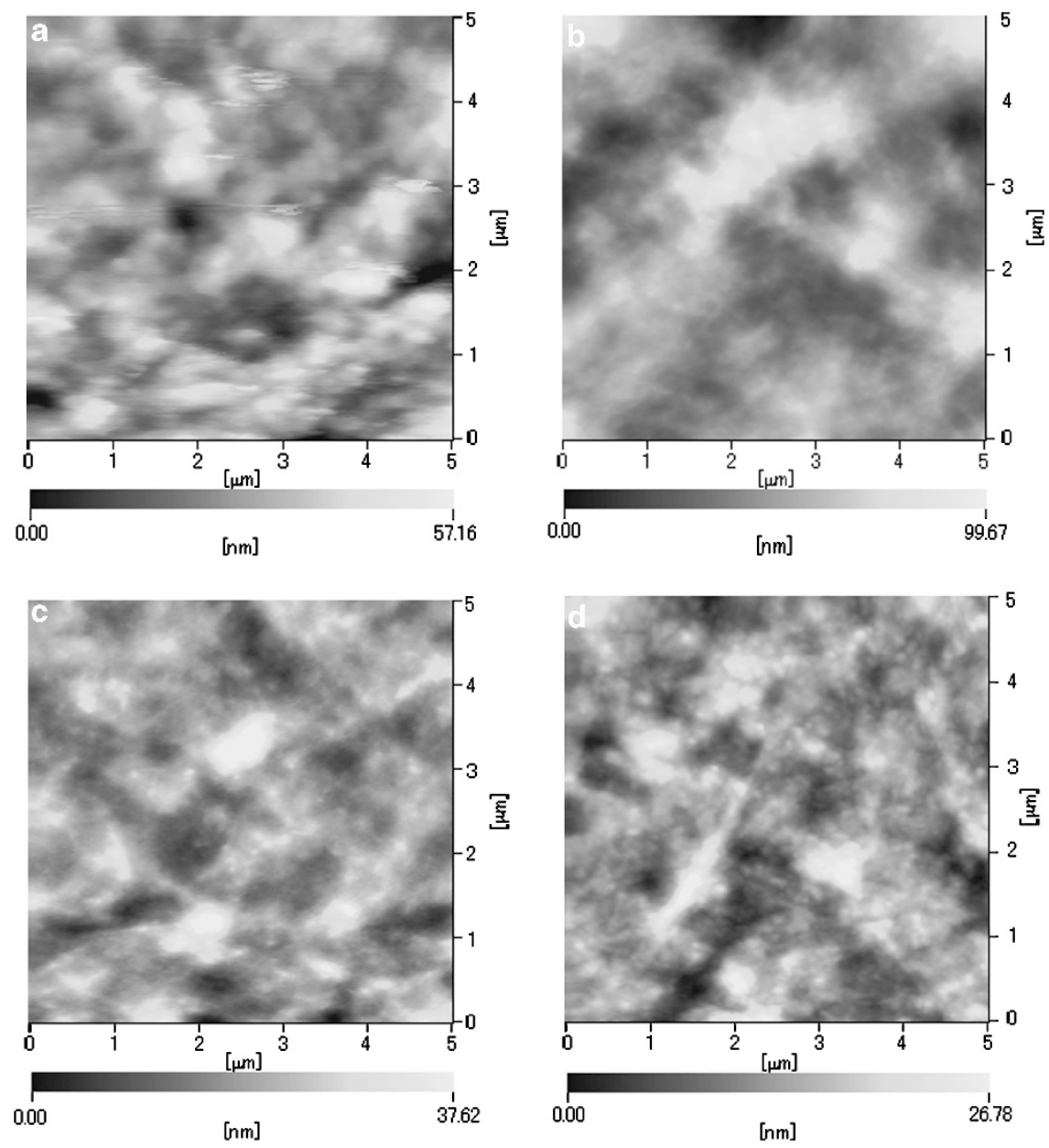

Figure 2 Atomic force microscopy images $\left(5 \times 5 \mu \mathrm{m}^{2}\right)$ of $\mathrm{P} 3 \mathrm{HT}: \mathrm{PC}_{60} \mathrm{BM}$ (1:1) films using (a) R- $M_{\mathrm{w}}$ $\mathrm{P} 3 \mathrm{HT}$, (b) $\mathrm{L}-M_{\mathrm{w}} \mathrm{P} 3 \mathrm{HT}$, (c) $\mathrm{M}-M_{\mathrm{w}} \mathrm{P} 3 \mathrm{HT}$ and (d) $\mathrm{H}-M_{\mathrm{w}} \mathrm{P} 3 \mathrm{HT}$. A full color version of this figure is available at Polymer Journal online.

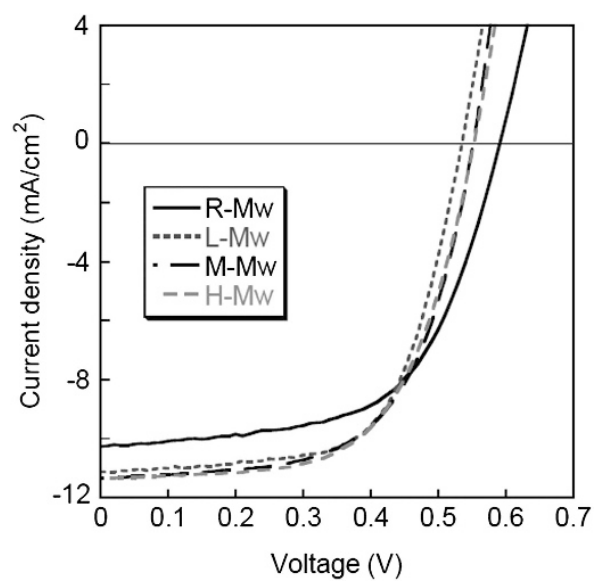

Figure $3 \mathrm{~J}-V$ curves of OPVs based on $\mathrm{P} 3 \mathrm{HT}: \mathrm{PC}_{60} \mathrm{BM}$ (1:1) films fabricated by spin coating from o-DCB solutions at 600 r.p.m. for $60 \mathrm{~s}$ and then annealed at $110^{\circ} \mathrm{C}$ for $10 \mathrm{~min}$. A full color version of this figure is available at Polymer Journal online. different values for $M_{\mathrm{w}}$. The $J-V$ curves show nearly the same shapes for all OPVs. Photovoltaic parameters for ITO/PEDOT:PSS $(40 \mathrm{~nm}) / \mathrm{BHJ}$ layer/LiF $(1 \mathrm{~nm}) / \mathrm{Al} \quad(80 \mathrm{~nm})$ OPVs under $100 \mathrm{~mW} \mathrm{~cm}^{-2}$ of simulated AM 1.5 solar irradiation are summarized in Table 2. The enhanced red-light absorption of the L- $M_{\mathrm{W}}$ P3HT film observed in Figure 1 might lead to higher PCEs compared with $\mathrm{M}-M_{\mathrm{w}}$ and $\mathrm{H}-M_{\mathrm{w}}$ P3HT. However, only slight fluctuations were observed in the PCEs for all OPVs fabricated by the procedures described in this study. Although polymer aggregates in the L- $M_{\mathrm{w}}$ P3HT film lead to enhanced red-light absorption, charge transport between the aggregates is consequently hindered. On the other hand, the long polymer chains of $\mathrm{M}-M_{\mathrm{w}}$ and $\mathrm{H}-M_{\mathrm{w}} \mathrm{P} 3 \mathrm{HT}$ can soften polymer aggregates and prevent charge-carrier trapping at the boundaries between polymer aggregates by creating a continuous pathway through the film. ${ }^{19}$ In this way, the slight fluctuations observed in the PCEs for the OPVs may be due to the balance of enhanced red-light absorption in the L- $M_{\mathrm{W}}$ P3HT film and enhanced carrier mobility through the $\mathrm{M}-M_{\mathrm{w}}$ and $\mathrm{H}-M_{\mathrm{w}}$ P3HT film.

\section{CONCLUSION}

In summary, we demonstrated that the amounts of both $\mathrm{P} 3 \mathrm{HT}$ and $\mathrm{PC}_{60} \mathrm{BM}$ materials in the fabrication process of $\mathrm{BHJ}$ layers can be much reduced by using a highviscosity solution of P3HT. The P3HT solution used in this study had the highest $M_{\mathrm{w}}$ (680900) used to date, to our knowledge. To obtain 250-nm-thick BHJ layers under identical fabrication conditions, the required concentrations of P3HT: $\mathrm{PC}_{60} \mathrm{BM}$ were $20 \mathrm{mg}: 20 \mathrm{mg} \mathrm{ml}^{-1}$ for L- $M_{\mathrm{w}}$ P3HT and $9 \mathrm{mg}: 9 \mathrm{mg} \mathrm{ml}^{-1}$ for $\mathrm{H}-M_{\mathrm{w}}$ P3HT. Finally, only slight fluctuations were observed in PCEs of around $3.8 \%$ for all OPVs based on P3HT with $M_{\mathrm{w}}$ ranging from 46600 to 680900.

\section{ACKNOWLEDGEMENTS}

We thank Dr Sugiyasu and Dr Ogi for their help in recording viscosity measurements.

Takeshi Yasuda ${ }^{1}$, Hikaru Meguro ${ }^{2}$, Shuji Okamoto ${ }^{2}$ and Lyuan Han ${ }^{1}$

${ }^{1}$ Organic Thin-Film Solar Cells Group, Photovoltaic Materials Unit, National Institute for Materials Science (NIMS), Tsukuba, Japan and ${ }^{2}$ Performance Material Department, Soken Chemical \& Engineering Co., Ltd.,

Sayama, Japan

E-mail:YASUDA.Takeshi@nims.go.jp 
1 Li, G., Zhu, R. \& Yang, Y. Polymer solar cells. Nat. Photon. 6, 153-161 (2012).

2 Yonezawa, K., Kamioka, H., Yasuda, T., Han, L. \& Moritomo, Y. Fast carrier formation from acceptor exciton in low-gap organic photovotalic. Appl. Phys. Express 5, 042302 (2012).

3 Yasuda, T., Shinohara, Y., Matsuda, T., Han, L. \& Ishi-I, T. Improved power conversion efficiency of bulk-heterojunction organic solar cells using a benzothiadiazole-triphenylamine polymer. J. Mater. Chem. 22, 2539-2544 (2012).

4 Beaujuge, P. M. \& Fréchet, J. M. J. Molecular design and ordering effects in $\pi$-functional materials for transistor and solar cell applications. J. Am. Chem. Soc. 133, 20009-20029 (2011).

5 Ohkita, H. \& Ito, S. Transient absorption spectroscopy of polymer-based thin-film solar cells. Polymer $\mathbf{5 2}$ 4397-4417 (2011).

6 Shen, X., Chen, S., Xiao, Z., Zuo, Q., Chen, Y. \& Ding, L. Synthesis of thienoselenadiazole-containing conjugated copolymers and their application in polymer solar cells. Polym. J. 44, 978-981 (2012).

7 Yasuda, T., Suzuki, T., Takahashi, M. \& Han, L. Airstable triarylamine-based amorphous polymer as donor material for bulk-heterojunction organic solar cells. Sol. Energy Mater. Sol. Cells 95, 3509-3515 (2011).
8 Nielsen, T. D., Cruickshank, C., Foged, S. Thorsen, J. \& Krebs, F. C. Business, market and intellectual property analysis of polymer solar cells. Sol. Energy Mater. Sol. Cells 94, 1553-1537 (2010)

9 Matsuo, Y., Hatano, J., Kuwabara, T. \& Takahashi, K Fullerene acceptor for improving open-circuit voltage in inverted organic photovoltaic devices without accom panying decrease in short-circuit current density. Appl. Phys. Lett. 100, 063303 (2012)

$10 \mathrm{Wu}$, Z., Song, T., Jin, Y. \& Sun, B. High performance solar cell based on ultra-thin poly(3-hexylthiophene) fullerene film without thermal and solvent annealing. Appl. Phys. Lett. 99, 143306 (2011).

11 Dang, M. T., Hirsch, L. \& Wantz, G. P3HT:PCBM, best seller in polymer photovoltaic research. Adv. Mater. 23, 3597-3602 (2011).

12 Dennler, G., Scharber, M. C. \& Brabec, C. J. Polymer fullerene bulk-heterojunction solar cells. Adv. Mater. 21, 1323-1338 (2009).

$13 \mathrm{Ma}$, W., Kim, J. Y., Lee, K. \& Heeger, A. J. Effect of the molecular weight of poly(3-hexylthiophene) on the morphology and performance of polymer bulk heterojunction solar cells. Macromol. Rapid Commun. 28 1776-1780 (2007)

14 Schilinsky, P., Asawapirom, U., Scherf, U., Biele, M. \& Brabec, C. J. Influence of the molecular weight of poly(3-hexylthiophene) on the performance of bulk heterojunction solar cells. Chem. Mater. 17, 2175 2180 (2005)

15 Hiorns, R. C., De Bettignies, R., Leroy, J., Bailly, S., Firon, M., Sentein, C., Khoukh, A., Preud'homme, H. \& Dagron-Lartigau, C. High molecular weights, polydispersities, and annealing temperatures in the optimization of bulk-heterojunction photovoltaic cells based on poly(3-hexylthiophene) or poly(3-butylthiophene). Adv. Funct. Mater. 16, 2263-2273 (2006).

16 Chen, T. A. \& Rieke, R. D. The first regioregular head-totail poly(3-hexylthiophene-2,5-diyl) and a regiorandom isopolymer: nickel versus palladium catalysis of 2(5)bromo-5(2)-(bromozincio)-3-hexylthiophene polymerization. J. Am. Chem. Soc. 114, 10087-10088 (1992).

17 Krebs, F. C. Fabrication and processing of polymer sola cells: A review of printing and coating techniques. Sol. Energy Mater. Sol. Cells 93, 394-412 (2009).

18 Kim, Y., Cook, S., Tuladhar, S. M., Choulis, S. A. Nelson, J., Durrant, J. R., Bradley, D. D. C., Giles, M., McCulloch, I., Ha, C.-S. \& Ree., M. A strong regioregularity effect in self-organizing conjugated polymer films and high-efficiency polythiophene:fullerene solar cells. Nat. Mater. 5, 197-203 (2006).

19 Kline, R. J., McGehee, M. D., Kadnikova, E. N., Liu, J., Fréchet, J. M. J. \& Toney, M. F. Dependence of regioregular poly(3-hexylthiophene) film morphology and field-effect mobility on molecular weight. Macromolecules 38, 3312-3319 (2005). 